\title{
Compact Ultra-Wide-Band HI Monopole Antenna Loaded with C-Shaped Parasitic Elements for DVB-T and LTE Applications
}

Miércio C. de Alcântara Neto ${ }^{1}$ (D) Gervásio P. S. Cavalcante ${ }^{1}$ (D), Rodrigo M. S. de Oliveira $^{1}$ (D), Fábio

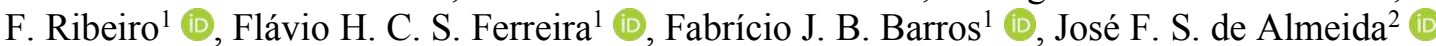
${ }^{1}$ Institute of Technology,Federal University of Pará,Brazil,miercio@ufpa.br, gervasio@ufpa.br, rmso@ufpa.br,fabioribeiro6zipmail@gmail.com, henryferreira014@gmail.com, fbarros@ufpa.br ${ }^{2}$ CyberSpace Institute, Federal Rural University of Pará, Brazil, felipe.almeida@ufra.edu.br

\begin{abstract}
In this work, a compact ultra-wide-band microstrip antenna loaded with $C$-shaped parasitic elements, for Digital Video Broadcasting - Terrestrial (DVB-T) and LTE 450 / 700 signal reception, is designed and presented. The proposed antenna is named "HI Monopole", and its geometry has been designed to be simple, lightweight, and compact. Fabrication process is inexpensive and suitable for electronic gadgets. The HI Monopole operates with ultra-wide bandwidth characteristics, encompassing Digital Video Broadcasting - Terrestrial (DVB-T) standard (470890 MHz), LTE-450 and LTE-700 bands. This feature has been accomplished by inserting an indent in its ground plane, adjusting dimensions of the feeding line, and adding two C-shaped parasite elements onto the region posterior to the antenna's main radiating element. It was verified via electromagnetic measuring that this device is capable of covering the $429-1022 \mathrm{MHz}$ range. Hence, its total bandwidth is $593 \mathrm{MHz}$. The superior and inferior cutoff frequencies have been defined using the $-10 \mathrm{~dB}$ return loss reference level. Therefore, the proposed antenna can be employed for receiving DTV and LTE signals broadcasted in any country, independently of its adopted standard.
\end{abstract}

Index Terms - HI monopole, DVB-T, LTE, parasitic elements, ultra-wideband printed antenna.

\section{INTRODUCTION}

As a robust communication mechanism, television has had an important role in social and cultural development of several civilizations, along many decades, connecting citizens to their country and to the whole world. However, with the replacement of obsolete analogue VHF (Very High Frequency) system by the newest and digital UHF (Ultra High Frequency) TV standard, the substitution of equipment is inevitable in order to provide access to technically superior Digital TV (DTV) channels.

This analogue-to-digital transition (A/D) has occurred in various countries and, facing this scenario, researchers began to investigate different antenna configurations and designs aiming to improve signal reception characteristics for Digital Video Broadcasting - Terrestrial (DVB-T) standards. With that in mind, several models of DTV antennas, based on various shapes and design techniques, have been presented, with extra attention to the bandwidth in which the equipment operates [1]-[11]. 
Journal of Microwaves, Optoelectronics and Electromagnetic Applications, Vol. 19, No. 3, September 2020 DOI: http://dx.doi.org/10.1590/2179-10742020v19i3841

For UHF bands, the communication between devices has to operate with low-power solutions for minimizing interference with other wireless systems. In this context, the solutions must involve lowpower spectral density whilst making transmissions with high data rates possible, as well as a high performance in multi-path channels with high signal-to-noise ratios and present sufficient penetration levels through different types of dielectric materials.

Nevertheless, wideband requirements must be fulfilled by the compact lightweight receiving antennas in this kind of application. Receiving devices should be able to operate at various DVB-T spectral bands in existence around the world, such as: Integrated Services Digital Broadcasting Terrestrial (ISDB-T), 470-770 MHz; Advanced Television System Committee (ATSC), 470-860 MHz; Digital Terrestrial Multimedia Broadcast (DTMB), 470-860 MHz; and Digital Video Broadcasting - Terrestrial (DVB-T), 470-890 MHz. Seeking to meet those requirements, the authors in [1] proposed an asymmetric fork-like monopole antenna for DVB-T system, specifically for the 451-912 MHz frequency range. Thus, the device proposed in [1] reached the bandwidth of $461 \mathrm{MHz}$, which corresponds to $100 \%$ of DVB-T range.

More recently, the authors of the studies presented in [3]-[5] have proposed a monopole antenna integrated into its ground plane for receiving DTV signals. The device was loaded with parasitic elements to enhance its bandwidth. However, operation band therein defined was obtained using return loss threshold of $-6 \mathrm{~dB}$, which may cause signal reception problems, since only approximately $74.9 \%$ of the received power could be transferred to the receiving electronic device. In practice, reception could also be affected by interference caused by other systems, thus further lowering that percentage. Despite the faulty cutoff criterion, the greatest bandwidth reached by the prototype is 510 MHz.

In [6] a low-profile wideband planar antenna for DTV reception is proposed. It is capable of operating with $390 \mathrm{MHz}$ bandwidth, approximately. Still, to reach the antenna's most robust configuration, a high complexity multilayered geometrical configuration was necessary to achieve the bandwidth design goals.

A compact internal antenna for handheld devices and its DTV applications have been discussed in [7], but authors also consider cutoff to be $-6 \mathrm{~dB}$ and achieve a bandwidth of $390 \mathrm{MHz}$ with the constructed prototype. Besides, the device is also geometrically complex, as far as many antenna noncoplanar parts must be integrated to attain high performance.

A novel metal-plate monopole antenna for DTV application is proposed in [8], in which the device is able to cover entirely the $468-880 \mathrm{MHz}$ band. However, it is not so compact and only external installation is possible.

Authors in [9]-[11] have suggested compact monopole antennas for DTV operation, which are printed upon fiberglass/glass epoxy substrate (FR-4). The miniaturized dimensions make these prototypes possible to install internally into electronic devices, such as television sets and tablets. But the antenna in [9], despite its reduced dimensions $(35 \times 117.5 \times 1.57 \mathrm{~mm})$, is able to cover only the Brazilian Microwave and Optoelectronics Society-SBMO received 27 April 2020; for review 7 May 2020; accepted 2 July 2020 Brazilian Society of Electromagnetism-SBMag $\quad$ C 2020 SBMO/SBMag $\quad$ (cc)) BY 
Journal of Microwaves, Optoelectronics and Electromagnetic Applications, Vol. 19, No. 3, September 2020

\section{7-818 MHz spectrum.}

To reach a device with wider bandwidth, [10] and [11] display an addition of sleeve-type parasitic elements to its respective antennas, positioned by the side of their main radiators. For [10], the dimensions achieved are $45 \times 154 \times 1.57 \mathrm{~mm}$ providing a 459-801 MHz operation band. And, in [11], the device presents dimensions of $48 \times 240 \times 1.57 \mathrm{~mm}$, operating in the $455-733 \mathrm{MHz}$ band.

When exploring new materials and geometric patterns with the purpose of achieving greater antenna operating bandwidth, the authors in [12] proposed in their study the design of an ultra-wideband textile antenna. According to the authors, their antenna would be capable to cover the entire 200$800 \mathrm{MHz}$ frequency range. However, there are serious discrepancies between the measurements and the results obtained with the simulated model for the return loss, since there are several crossings of the $-10 \mathrm{~dB}$ cut-off threshold in the experimental curve. Thus, it may be said that it is not possible to consider $-10 \mathrm{~dB}$ as cut-off threshold to define the bandwidth of that device.

In this context, in the study proposed in this paper it is designed a HI Monopole-type antenna to cover $100 \%$ of the DVB-T standard band, and the bands of LTE-450 and LTE-700 [13]. This project was developed so that the device, in a single structure, displays characteristics such as: ultra-wideband operation, low complexity design and simple geometry, compactness, lightweight and inexpensive fabrication that can be easily integrated into the housing of electronic equipment.

For return loss measurements, two epoxy glass substrate prototypes of the device have been built, both with dimensions of $48 \times 152.5 \times 1.57 \mathrm{~mm}$. With these physical parameters, it is verified that the HI Monopole with C-shaped parasite load configuration is capable of operating within the band 429$1022 \mathrm{MHz}$ (593 MHz of bandwidth), i.e., the device is an ultra-wide-band antenna. The antenna design details are discussed in Section 2. Simulated and measured results are presented in Section 3, and Section 4 holds the conclusions of this work.

\section{ANTENNA DESIGN}

The HI Monopole geometry was originally proposed in [14]. The antenna's geometry was developed according to studies on the classic planar monopole antenna, and by taking into account the fact that electrical current flows only through the metallic border of the patch due to the influence of the skin effect on electromagnetic (EM) waves interacting with metal. Thus, the radiator is formed using a closed metallic loop along with a central coplanar metallic conductor connecting two opposite sides of the loop, as Fig. 1 precisely defines. The central conductor has the purpose of balancing magnetic fields produced by the loop sides oriented parallelly to that conductor, improving impedance matching as a consequence [14]. The name "HI" is due to the geometrical similarity between the antenna's metallic patch and the Japanese kanji ideogram HI, 日(pronounced as he), which means sun or day. Figure 1 presents a schematic of the HI Monopole and of the produced magnetic fields. 


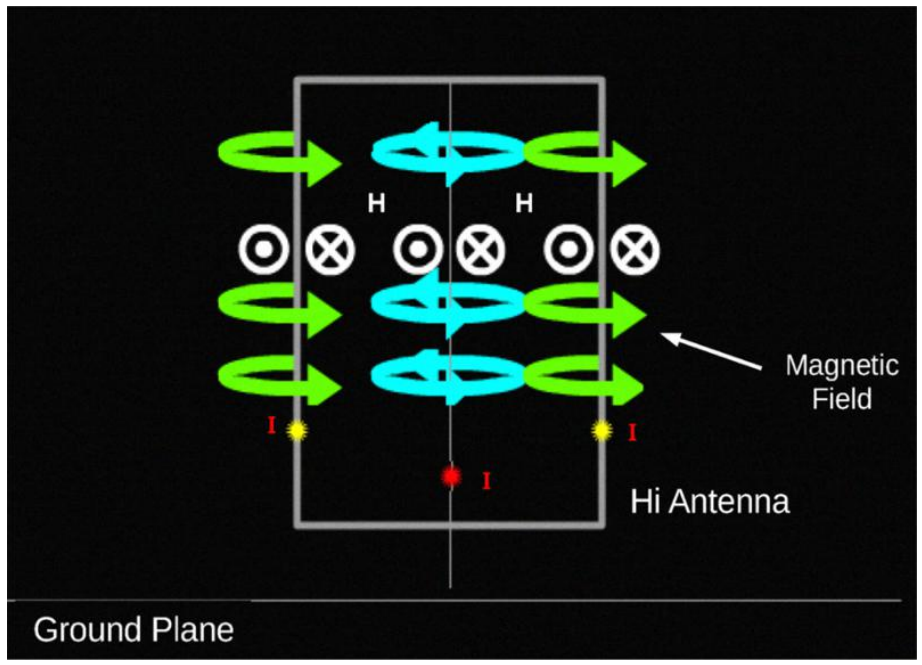

Fig. 1. Geometry of HI monopole and representation of the magnetic field due to current flows of HI antenna [14].

Differently from the antenna presented in [14], the device proposed in this work has been designed to be printed on fiberglass substrate (FR-4), in a compact manner so it can be integrated into the inner part of electronic devices such as television sets and tablet computers. Figure 2 presents the compact and ultra-wide-band HI Monopole geometry designed in this paper. In Figure 2a, we have the following parts and dimensions indicated: (1) the main radiator element (patch) of the device: patch height is $\mathrm{Ha}$ and its width is Wa, metallic strip borders measuring $2 \mathrm{~mm}$ in width, and main central conductor filament of which width measures $0.5 \mathrm{~mm}$; (2) glass epoxy substrate (FR-4), with dimensions $48 \times 152.5 \times 1.57 \mathrm{~mm}$; (3) feeding line, of which line height is $\mathrm{Hf}$ and line width is Wf, in accordance with the structure presented in [10]; (4) ground plane notch in order to match the device impedance with $50 \Omega$, as seen in [9], measuring length $\mathrm{L}$ and width $\mathrm{W}$; and, finally, (5) the ground plane with height $\mathrm{Hg}$ and width $\mathrm{Wg}$.

Figure $2 \mathrm{~b}$ shows the antenna side opposite to the side on which the main radiator element is printed, and it highlights: (6) both C-shaped symmetric parasitic elements, each one turned against each other, with height $\mathrm{Hp}$ and width $\mathrm{Wp}$. The $\mathrm{C}$-shaped parasitic elements are made using conductive strips measuring $2 \mathrm{~mm}$ in width. The distances from the parasitic elements $(6 \mathrm{~A})$ and $(6 \mathrm{~B})$ to ground plane is given by Gpp and gap, respectively. The Gpl parameter is the distance measured from the parasitic elements $(6 \mathrm{~A})$ or $(6 \mathrm{~B})$ to the substrate borders.

The ultra-wide-band performance of the proposed antenna is reached due to excitation of two resonating modes. The first mode is controlled directly by the radiator geometry (length, width and central conductor), as well as by the ground plane dimensions. The second mode is produced mainly by the C-shaped parasites positioned on the opposite side of the board (see Fig. 2). Ultra-wide-band impedance matching was obtained mainly by optimizing dimensions of feeding line, ground plane and parasites. All the optimized geometric parameters of the proposed devices are given in Table I. Figure 3 presents the fabricated HI Monopole prototype. 
Journal of Microwaves, Optoelectronics and Electromagnetic Applications, Vol. 19, No. 3, September 2020 DOI: http://dx.doi.org/10.1590/2179-10742020v19i3841

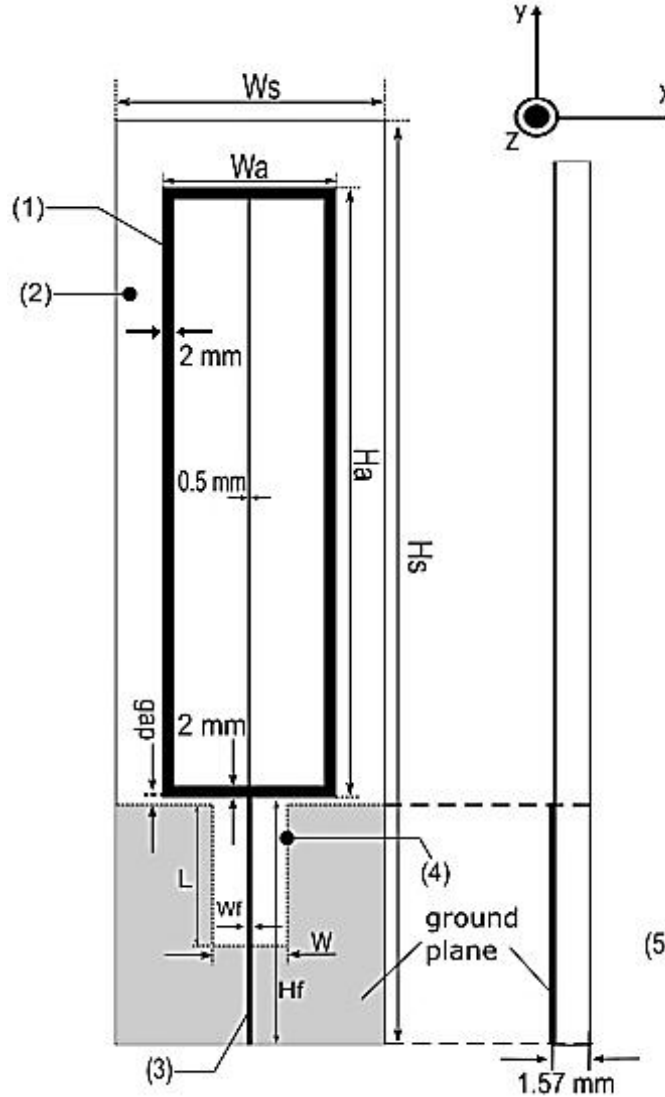

(a)

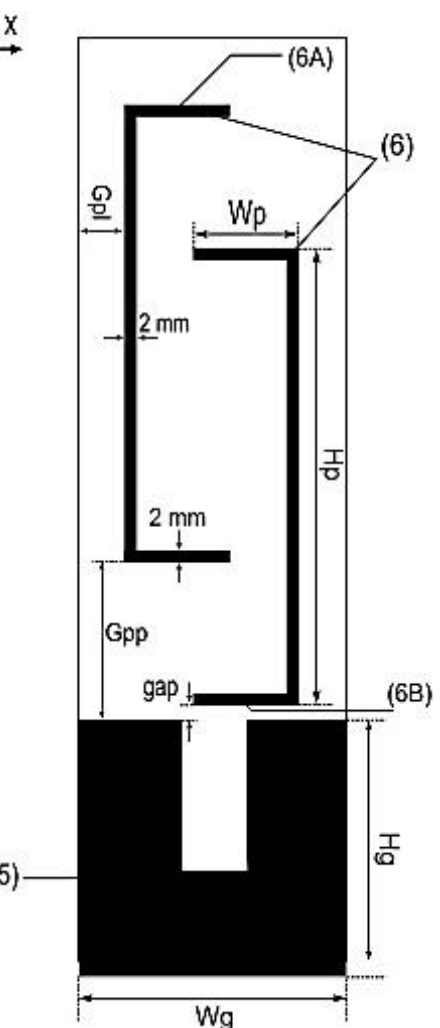

(b)

Fig. 2. The geometry of the proposed antenna: (a) frontal view and (b) back view.

TABLE I. HI-ANTENNA'S GEOMETRIC PARAMETERS IN MILLIMETERS

\begin{tabular}{cc|cc}
\hline \multicolumn{2}{c|}{ Figure 2a } & \multicolumn{2}{c}{ Figure 2b } \\
\hline Parameter & Value & Parameter & Value \\
\hline Ws & 48 & $\mathrm{Wp}$ & 17.25 \\
$\mathrm{Wa}$ & 25 & $\mathrm{Hp}$ & 75 \\
$\mathrm{Ha}$ & 110 & $\mathrm{Wg}$ & 48 \\
$\mathrm{Hs}$ & 152.5 & $\mathrm{Hg}$ & 42.5 \\
$\mathrm{Hf}$ & 35.5 & gap & 3 \\
Wf & 3 & Gpp & 38 \\
L & 29 & Gpl & 11.75 \\
W & 9.5 & -- & -- \\
\hline
\end{tabular}

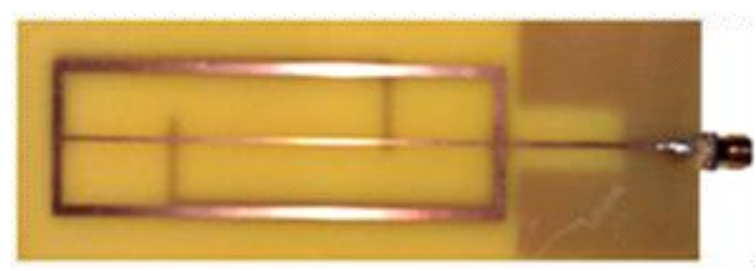

(a)

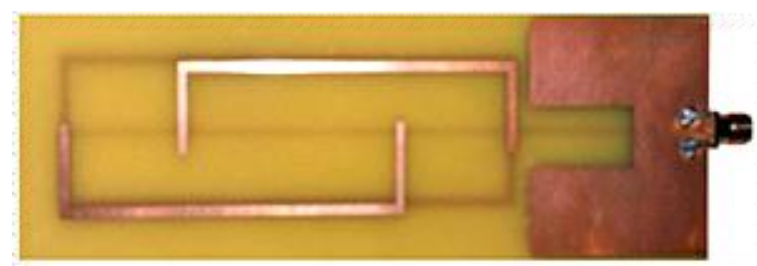

(b)

Fig. 3. HI Monopole Prototype: (a) frontal view and (b) back view. 
Journal of Microwaves, Optoelectronics and Electromagnetic Applications, Vol. 19, No. 3, September 2020 DOI: http://dx.doi.org/10.1590/2179-10742020v19i3841

\section{RESULTS AND DISCUSSIONS}

The main antenna parameters have been studied and optimized to obtain satisfactory results. The EM properties of two categories of antennas were calculated using the Finite Element Method (FEM), with the aid of the commercial software HFSS. The first class of antenna was conceived without the ground plane notch and with no loaded parasitic elements, i.e., it has just the main HI radiator element and a rectangular ground strip printed on the surface opposite to the antenna's patch side. The second class of antenna analyzed is the proposed antenna, depicted by Fig. 2, with all its constituent parts, designed for achieving ultra-wide-band operation characteristics. In both cases, the antennas are printed on FR-4 substrate, which is characterized by relative permittivity $\varepsilon_{r}=4.4$, loss tangent $\delta=$ 0.02 and thickness $\mathrm{h}=1.57 \mathrm{~mm}$. Validation of numerically obtained return losses are carried out via measurements conducted using Anritsu Site Master S331C. Figure 4 shows the measurement setup, consisting of the antenna connected to the measuring equipment.

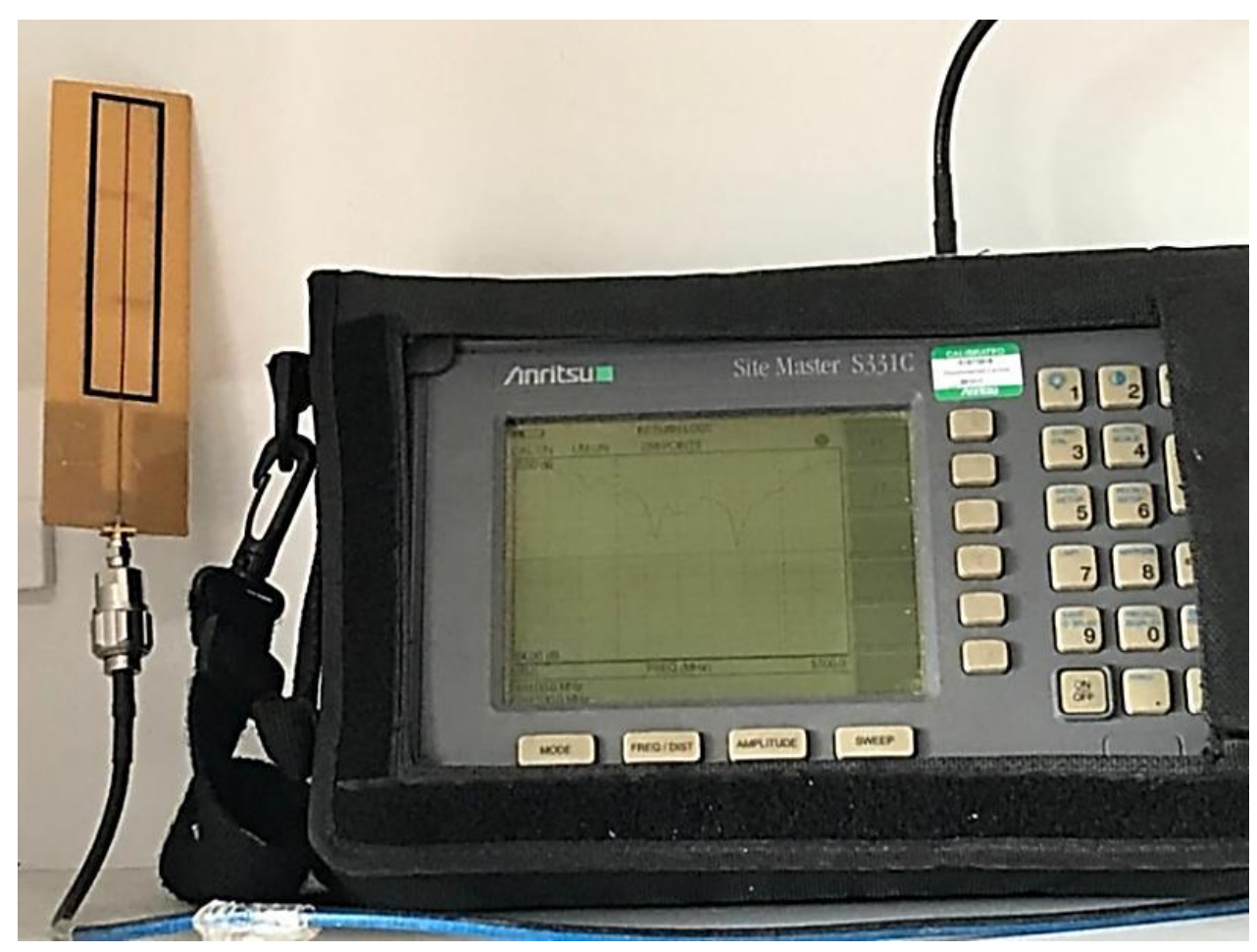

Fig. 4. The return loss measurement setup.

Figure 5 presents the simulated and measured return losses for the first antenna configuration (without the C-shaped parasite elements and with absence of notches in its rectangular ground strip). Return losses measured and simulated for the second class of antenna (as fully depicted by Fig. 2) can be seen in Fig. 6. 


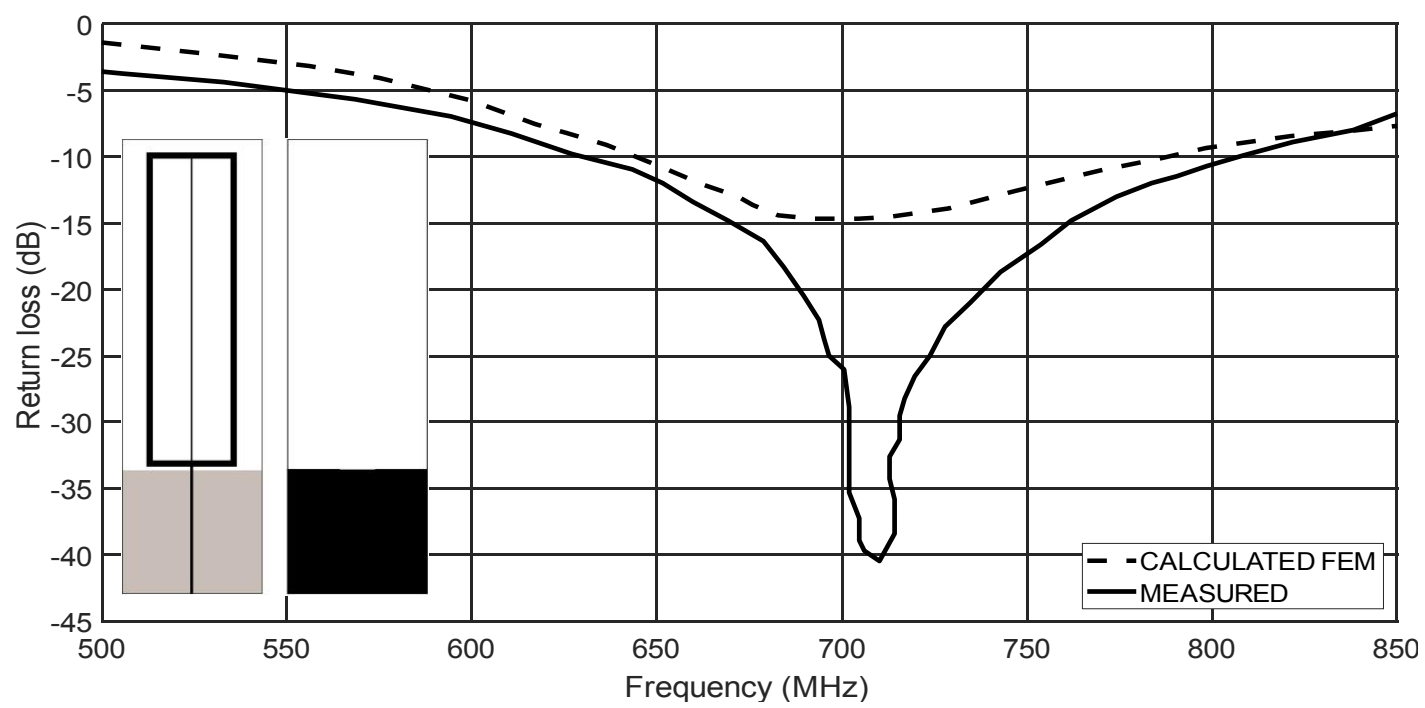

Fig. 5. Simulated and measured return losses for the first type of antenna (without C-shaped parasitic elements and rectangular ground strip).

In Figs. 5 and 6, proper agreement is observed between the measured and simulated data. By inspecting Fig. 5, one may say that measured curve shows that the HI monopole without parasitic elements and not aided with ground plane notch is able to cover the frequency range $643.3-805 \mathrm{MHz}$, yielding a bandwidth of $161.7 \mathrm{GHz}$, covering $~ 38 \%$ of the DVB-T standard frequency band. According to Fig. 6, the antenna loaded with the parasitic elements is able to operate in the range 429-1022 GHz, i.e., it has a bandwidth of $593 \mathrm{MHz}$, covering $100 \%$ of the frequency range of the DVB-T standard and, additionally, it encompasses the bands of LTE-450 and LTE-700 standards. Numerical results show a lower resonant mode at approximately $700 \mathrm{MHz}$ for the case of Fig. 5 and a higher resonant mode between $900 \mathrm{MHz}$ and $1 \mathrm{GHz}$ for the case of Fig. 6.

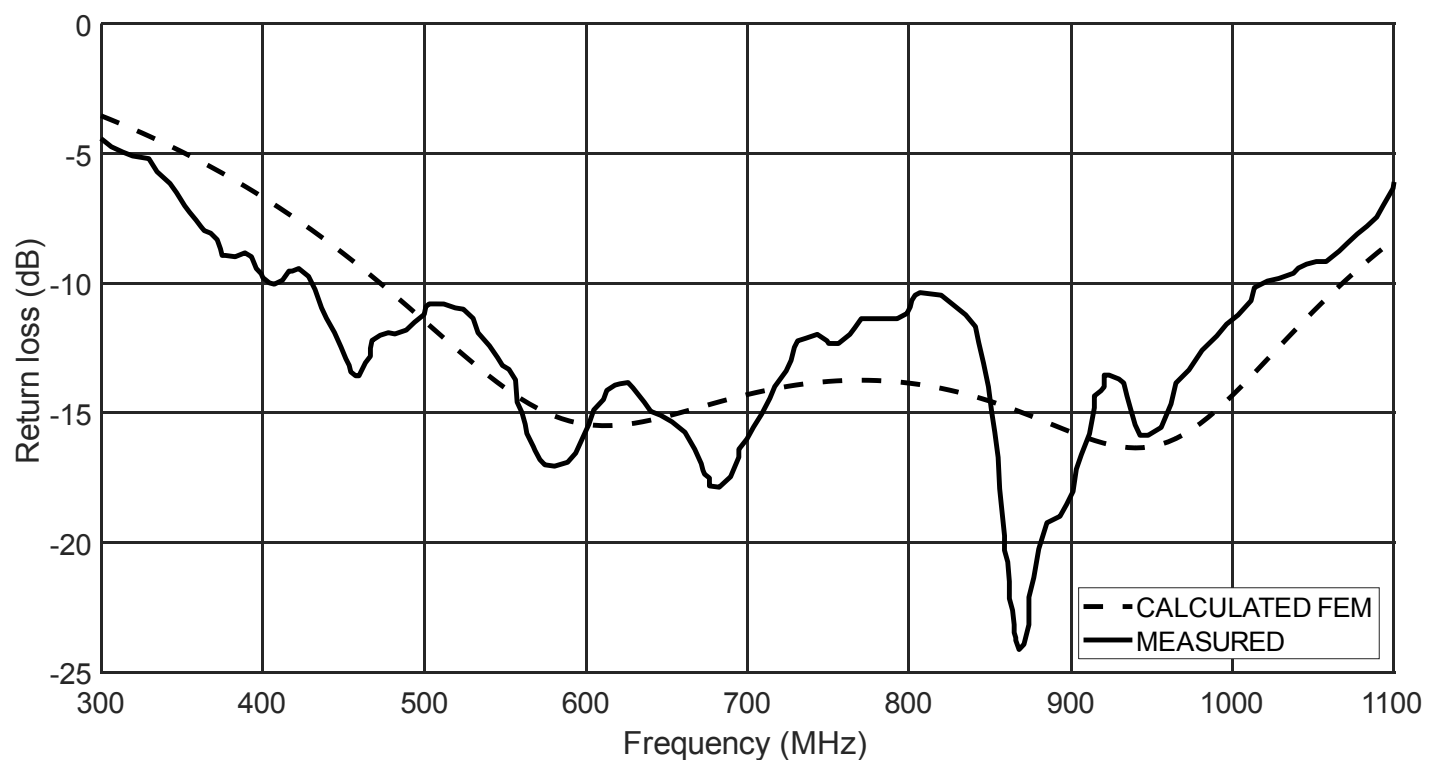

Fig. 6. Simulated and measured return losses for the HI Monopole antenna designed with C-shaped parasites and ground plane notch, acting as an ultra-wide band device. 
Lower resonance at approximately $700 \mathrm{MHz}$ (return loss in Figure 5) is directly influenced by the antenna's main radiator, with an approximate length of $0.25 \lambda$. With respect to the second resonant mode (at $\sim 990 \mathrm{MHz}$, return loss in Figure 6), one may say that it is directly influenced by the Cshaped parasite elements, also measuring approximately $0.25 \lambda$ for that frequency. These features result in the combination of both resonance modes in the proposed antenna, forming a wider bandwidth operation resulting from those superposed effects. This fact can be confirmed observing Figure 7, which shows the current density magnitude diagram for both resonating modes of the HI Monopole, for the proposed configuration, with the loaded C-shaped parasite elements and the ground plane notch. It is possible to see that lower frequencies tend to resonate with the HI patch and higher frequencies radiate with strong dependence on the $\mathrm{C}$-shaped parasites and the ground plane notch.

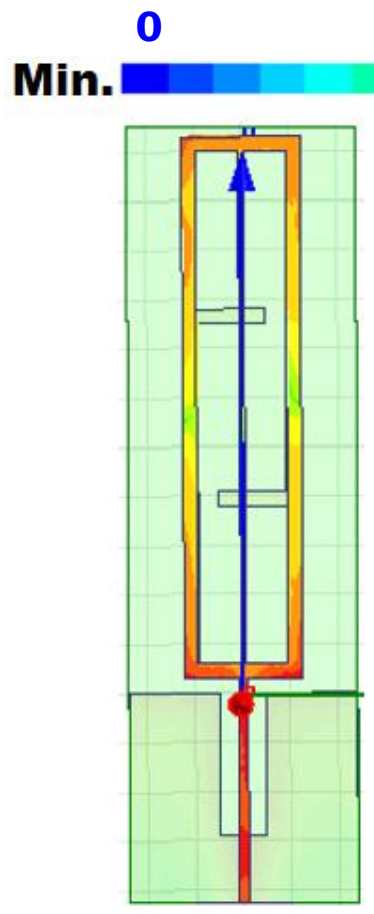

(a)
$100 \%$

\section{Max.}

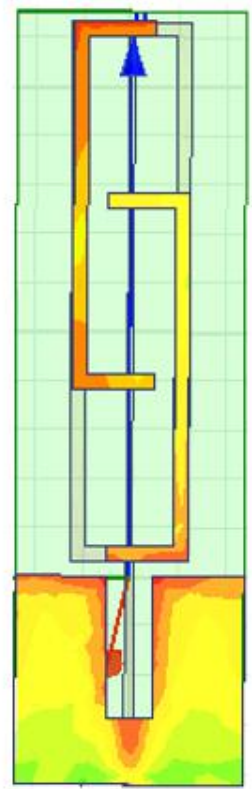

(b)

Fig. 7. Normalized current density distributions at: (a) $700 \mathrm{MHz}$ and (b) $990 \mathrm{MHz}$.

By analyzing the numerical result shown in Figure 5 and comparing it to Figure 6, we see that the lower resonant mode is shifted from $700 \mathrm{MHz}$ to $600 \mathrm{MHz}$. This can be justified by the electromagnetic mutual coupling among the main radiator and the parasitic elements, producing an increased effective electrical length of the radiator. The confined field within the substrate due to the introduction of the $\mathrm{C}$-shaped parasites also contributes to mold the resonance profile in Fig. 6.

During the parametric optimization process, it was possible to understand the influence of geometric parameters on the response of the device. Results plotted in Fig. 8 and Fig. 9 show the influence of ground plane dimensions $\mathrm{Hg}$ and $\mathrm{L}$, respectively. Other parameters of the device were 
Journal of Microwaves, Optoelectronics and Electromagnetic Applications, Vol. 19, No. 3, September 2020 DOI: http://dx.doi.org/10.1590/2179-10742020v19i3841

preserved as given in Table I. In Fig. 8, it is clear that increasing $\mathrm{Hg}$ from $32.5 \mathrm{~mm}$ to $52.5 \mathrm{~mm}$ tends to produce improved impedance matching. However, further increases of $\mathrm{Hg}$ are not beneficial to the device, as return losses increase. Notice that although $\mathrm{Hg}=52.5 \mathrm{~mm}$ produces smaller return losses, it does not provide the largest bandwidth, which is obtained when $\mathrm{Hg}=42.5 \mathrm{~mm}$. Fig. 9 clearly shows the benefits of the notch. As the notch depth $\mathrm{L}$ is increased, bandwidth is increased accordingly. The favorable effects observed from the ground plane optimization come from adjustments of current amplitude at the input terminal of the microstrip line over the frequency band as $\mathrm{Hg}$ and $\mathrm{L}$ are tuned, leading to beneficial variations of impedance at the antenna's input terminal [9]-[11], [15], [16].

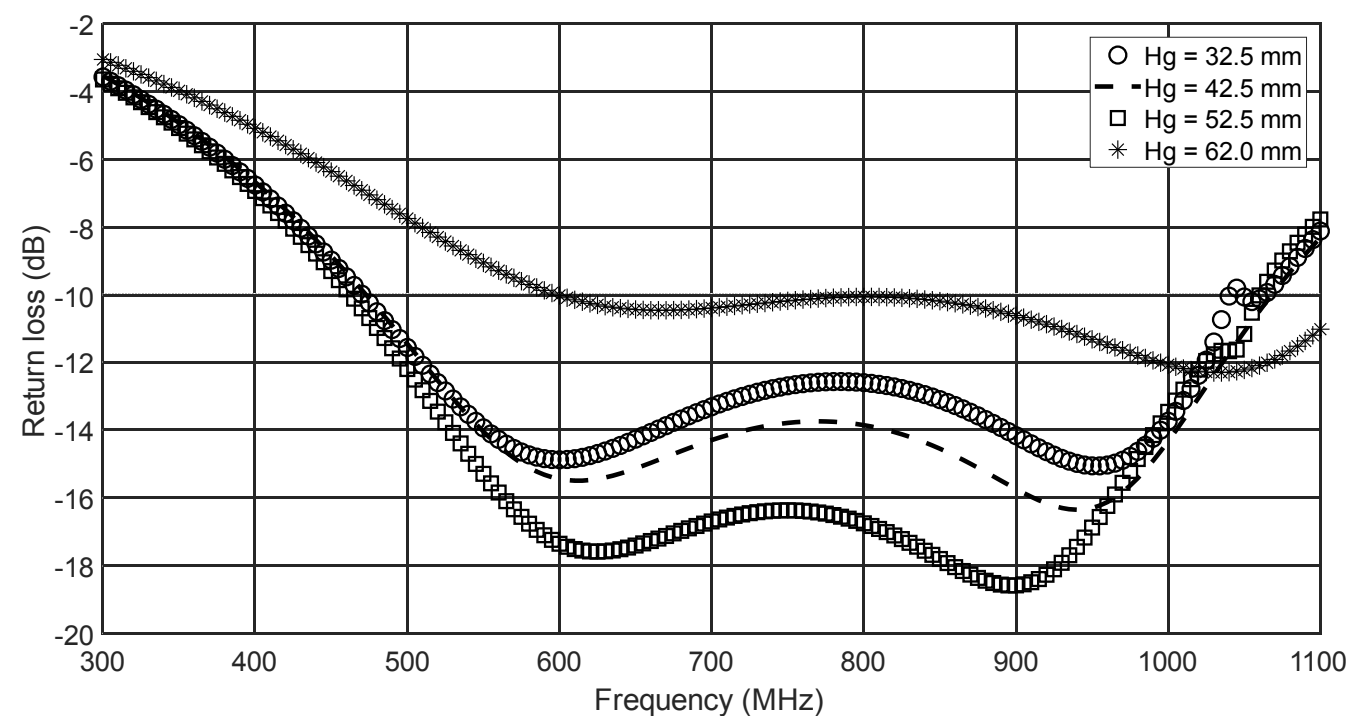

Fig. 8. Calculated return losses for various values of ground plane length $\mathrm{Hg}$ of the proposed HI Monopole antenna. All other parameters have been preserved.

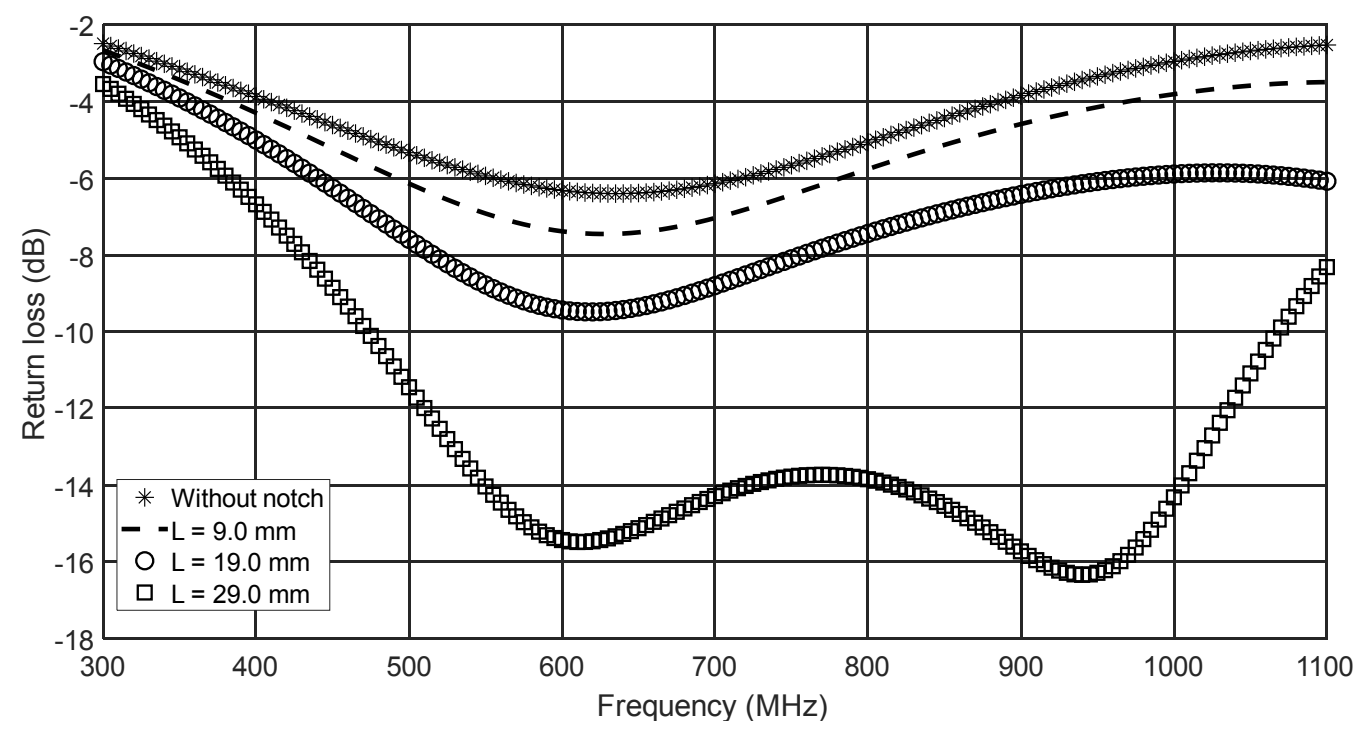

Fig. 9. Calculated return losses for various values of ground plane notch depth L of the proposed HI Monopole antenna. All other parameters have been preserved. 
Journal of Microwaves, Optoelectronics and Electromagnetic Applications, Vol. 19, No. 3, September 2020 DOI: http://dx.doi.org/10.1590/2179-10742020v19i3841

Figure 10 shows the calculated 2-D radiation patterns at $700 \mathrm{MHz}$ and $990 \mathrm{MHz}$ for the proposed antenna. The antenna presents nearly omnidirectional radiation patterns at different frequencies on the $x-y$ plane and dipole-like radiation patterns on the $y-z$ plane. These characteristics are similar to those observed for the conventional dipole for DVB-T. In addition, the cross-polarization patterns of the antenna present very lower levels on the three conventional coordinate planes.
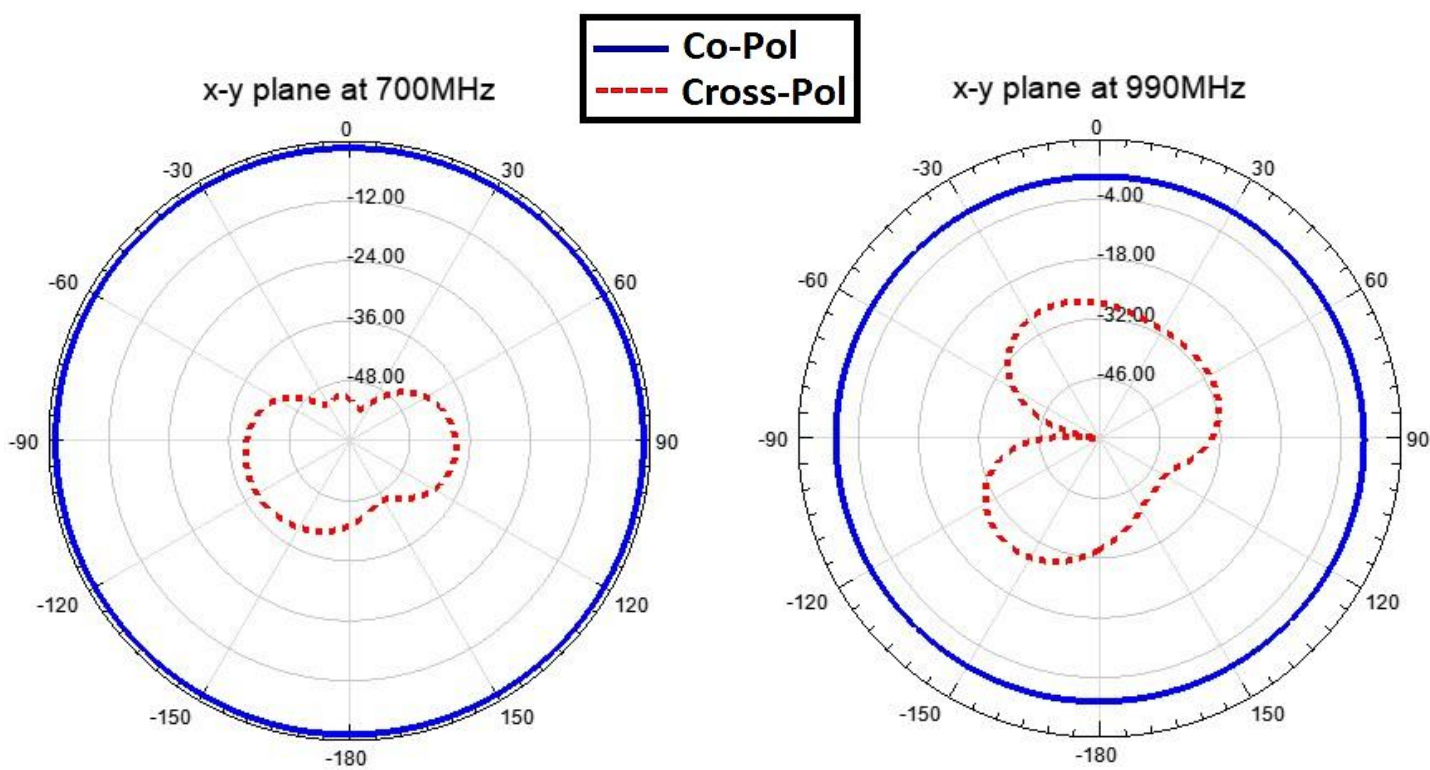

z-y plane at $700 \mathrm{MHz}$

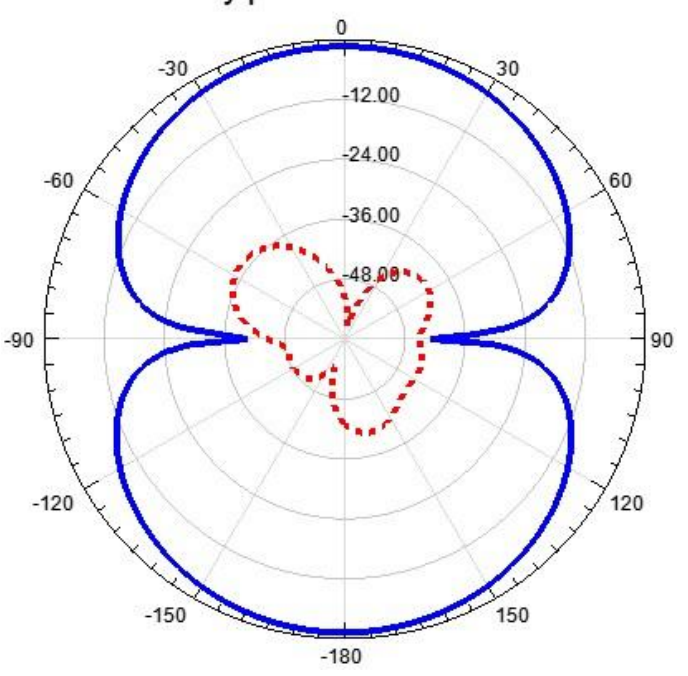

(a)

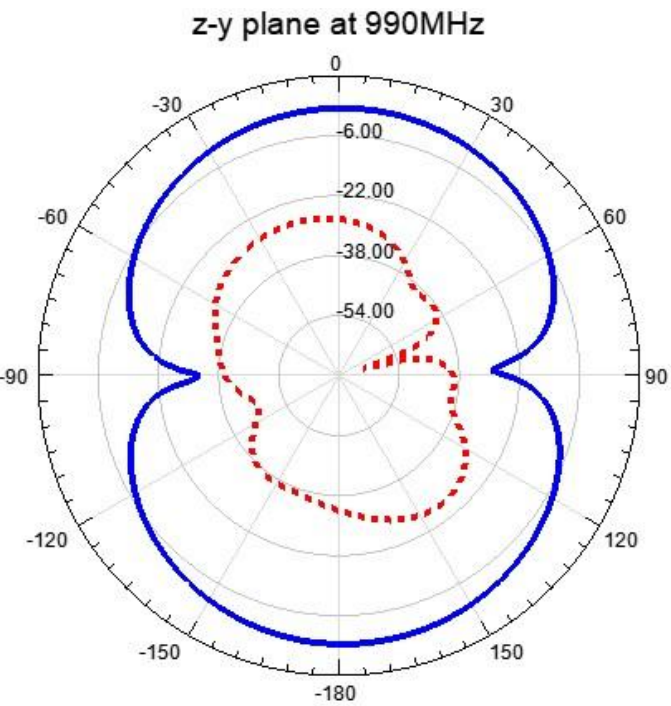

(b)

Fig. 10. Calculated radiation patterns of the proposed antenna at (a) $700 \mathrm{MHz}$ and (b) $990 \mathrm{MHz}$. 
Journal of Microwaves, Optoelectronics and Electromagnetic Applications, Vol. 19, No. 3, September 2020 DOI: http://dx.doi.org/10.1590/2179-10742020v19i3841

Figure 11 shows the calculated antenna peak gain over the $470-1075 \mathrm{MHz}$ band. This result shows that maximum gain increases with frequency in a range from 0.47 to $1.64 \mathrm{dBi}$.

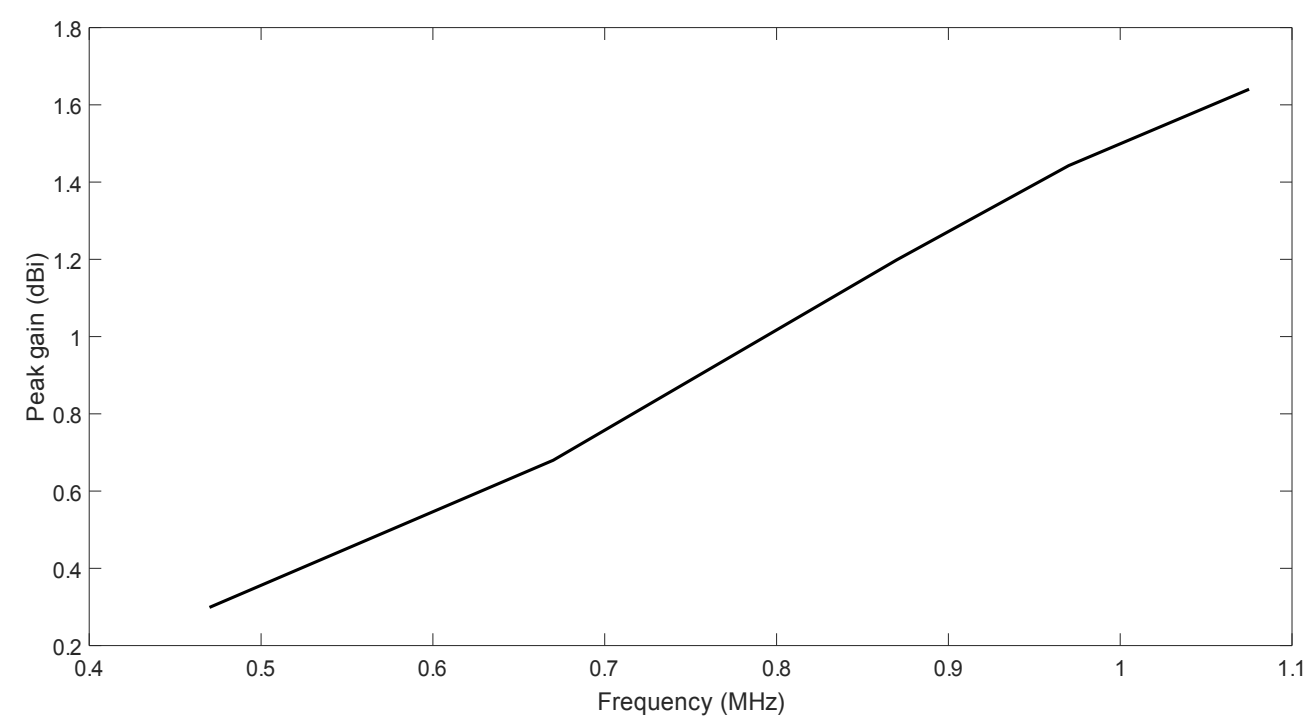

Fig. 11. Calculated antenna peak gains for the proposed device.

The calculated input impedance of the proposed antenna is shown by Fig. 12 between $100 \mathrm{MHz}$ and $1100 \mathrm{MHz}$. Notice that the real part of the impedance is relatively close to $50 \Omega$ over the shown frequency spectrum. Additionally, imaginary part is very close to zero over a significant part of the shown spectrum, especially between $450 \Omega$ and $950 \Omega$. These features indicate the impedance matching to the $50 \Omega$ load. As previously seen in Fig. 6, the operation band of the antenna is between 429 and $1022 \mathrm{MHz}$, which meets the $-10 \mathrm{~dB}$ criterion for the return loss.

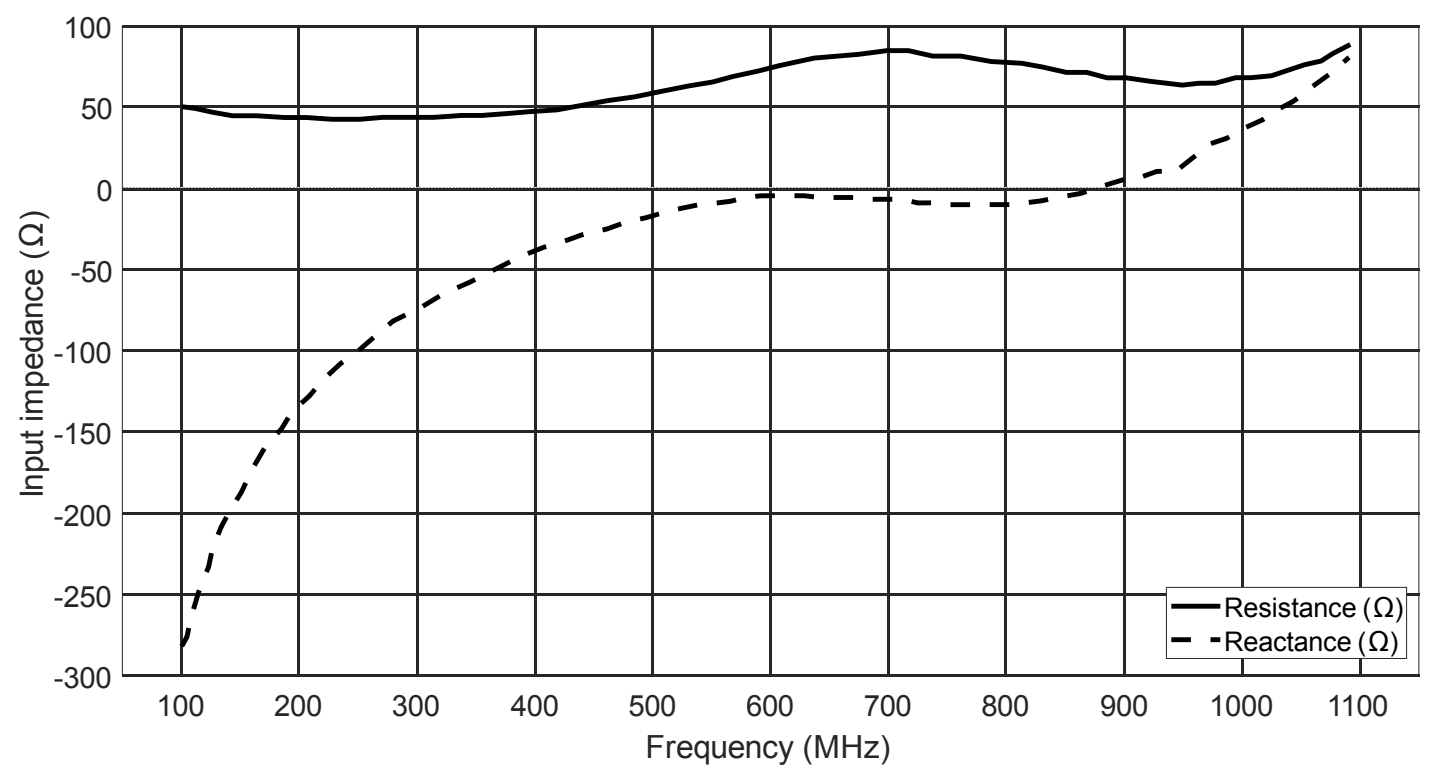

Fig. 12. Input resistance and reactance spectra of the proposed antenna. 
Journal of Microwaves, Optoelectronics and Electromagnetic Applications, Vol. 19, No. 3, September 2020 DOI: http://dx.doi.org/10.1590/2179-10742020v19i3841

Table 2 presents, with further details, a comparison among the operation and geometric characteristics of the antenna proposed in this work and those devices designed in [1]-[7], [9]-[11].

TABLE 2. COMPARISON AMONG VARIOUS ANTENNAS

\begin{tabular}{cccccc}
\hline Work & $\begin{array}{c}\text { Measured } \\
\text { coverage range } \\
\text { (MHz) }\end{array}$ & Bandwidth (MHz) & $\begin{array}{c}\text { Antenna Dimensions } \\
(\mathbf{m m})\end{array}$ & $\begin{array}{c}\text { Cutoff threshold } \\
\text { for defining } \\
\text { operation band } \\
\text { (dB) }\end{array}$ & $\begin{array}{c}\text { Coverage capacity } \\
\text { of DTV-T standard } \\
\text { (\%) }\end{array}$ \\
\hline Ref. [1] & $451-912$ & 461 & $35 \times 247 \times 0.8$ & -10 & 100 \\
Ref. [2] & $470-798$ & 328 & not specified & -10 & 78 \\
Ref. [3] & $430-940$ & 510 & $255 \times 9 \times 2$ & $>-6$ & Empty \\
Ref. [4] & $440-820$ & 380 & $976 \times 583 \times 5$ & $>-6$ & Empty \\
Ref. [5] & $460-870$ & 410 & $976 \times 583 \times 15.5$ & -10 & 76 \\
Ref. [6] & $470-790$ & 320 & $440 \times 440 \times 20$ & $>-6$ & Empty \\
Ref. [7] & $470-860$ & 390 & $80 \times 15 \times 10$ & -10 & 88 \\
Ref. [9] & $447-818$ & 371 & $35 \times 117 \times 1.57$ & -10 & 81 \\
Ref. [10] & $459-801$ & 342 & $45 \times 174 \times 1.57$ & -10 & 66 \\
Ref. [11] & $455-733$ & 278 & $48 \times 174 \times 1.57$ & -10 & 100 \\
This work & $429-1022$ & 593 & $48 \times 152.5 \times 1.57$ & & Empty \\
\hline
\end{tabular}

As demonstrated in Table 2, the HI Monopole proposed herein presents the largest operation bandwidth, i.e., it covers greater frequency range than other antennas in literature, even by adopting the $-10 \mathrm{~dB}$ cutoff criterion. The ground plane length $\mathrm{Hg}=42.5 \mathrm{~mm}$ was selected not just because of ultra-wide-band operation, but also because it allows for keeping the antenna design compact. When considering the antenna presented in [1], although it covers the entire range of the DVB-T standard, the HI antenna proposed in this work has a bandwidth about $132 \mathrm{MHz}$ larger than that device. Finally, with respect to Table 2, references [3-5] and [7] do not present their respective percentages of band coverage because the authors consider the cutoff threshold for defining the operation band of their devices above $-6 \mathrm{~dB}$.

\section{CONCLUSIONS}

A compact ultra-wide-band HI monopole antenna loaded with C-shaped parasitic elements for DVB-T and LTE applications has been developed and presented in this work. As verified from measured results, the designed HI Monopole antenna is capable of covering the 429-1022 MHz band, producing a corresponding fractional bandwidth of $81.74 \%$. Therefore, the device is an ultra-wideband antenna, since its fractional bandwidth is larger than $20 \%$. In addition, the HI monopole covers $100 \%$ of the frequency range of the DVB-T standard, i.e., it is capable of operating in any location in which digital TV signals are broadcasted today.

An interesting characteristic of this antenna is the miniaturization of its geometric dimensions, as well as the reduced size of its ground plane, which makes it feasible its installation inside electronic device's housing, mainly room television sets, portable TVs and tablet computers. The proposed device is highly recommended for DVB-T applications, given that its operation band is adequate to 
Journal of Microwaves, Optoelectronics and Electromagnetic Applications, Vol. 19, No. 3, September 2020 DOI: http://dx.doi.org/10.1590/2179-10742020v19i3841

several different broadcasting standards of different countries, therefore making it considerably superior to the antennas previously developed in literature.

\section{ACKNOWLEDGMENTS}

The authors thank the support of National Council for Scientific and Technological Development (CNPq), National Institute of Science and Technology in Wireless Communication (INCT-CSF), Coordination of Superior Level Staff Improvement (CAPES), Group of Telecommunications and Applied Electromagnetism (GTEMA) of the Federal Institute of Education, Science and Technology of Paraíba (IFPB), Federal University of Pará (UFPA) and Federal University of Rio Grande do Norte (UFRN).

\section{REFERENCES}

[1] C.-Y. Huang, B.-M. Jeng, C.-F. Yang, "Wideband monopole antenna for DVB-T applications," Electronics Letters, vol. 44, no. 25, pp. 1-2, December 2008.

[2] M. H. Jamaluddin, T. A. Rahman, H. Mohamad, N. Ramli, M. T. Islam, "Wideband planar u-shaped monopole antenna with meandering technique for TV white space application," Radioengineering, vol. 22, no. 3, pp. 708-713, September 2013.

[3] T. V. Trinh, C. W. Jung, "Compact broadband internal monopole antenna with parasitic strips and sleeve feed for UHDTV applications," IET Microwaves, Antennas \& Propagation, vol. 13, no. 12, pp. 2096-2101, July 2019.

[4] T. V. Trinh, T. Park, C. W. Jung, "Internal fork-shaped wideband monopole antenna with a parasitic sleeve for ultrahigh-definition television applications," Microw. Opt. Technol. Lett., vol. 61, no. 12, pp. 2725-2729, July 2019.

[5] T. V. Trinh, G. Kim, J. Kim, C. W. Jung, "Wideband internal PIFA-loop antenna designed on the bezel of digital television applications for UHF band," Electronics Letters, vol. 54, no. 22, pp. 1260-1262, November 2018.

[6] N. M. M. Hicho, E. A. Daviu, M. C. Fabrés, M. F. Bataller, "A novel low-profile high-gain UHF antenna using highimpedance surfaces," IEEE Antennas and Wireless Propagation Letters, vol. 14, pp. 1014-1017, January 2015.

[7] J. T. Yeh, W. J. Liao, S. H. Chang, "Compact internal antenna for handheld devices with comprehensive DTV band coverage," IEEE Transactions on Antennas and Propagation, vol. 62, no. 8, pp. 3998-4007, August 2014.

[8] L. Tan, G. Yan, "A novel metal-plate monopole antenna for DTV application," International Conference on Computational Intelligence and Communication Networks, pp. 14-16, November 2014.

[9] J. H. C. Morais, A. L. P. S. Campos, "Printed grating monopole antenna for DTV applications", SBMO/IEEE MTT-S International Microwave and Optoelectronics Conference (IMOC), pp. 213-216, November 2011.

[10] H. D. Chen, "Compact broadband microstrip-line-fed sleeve monopole antenna for DTV application and ground plane effect," IEEE Antennas and Wireless Propagation Letters, vol. 7, pp. 497-500, August 2008.

[11] H. D. Chen, "Ground plane effects on the microstrip-line-fed broadband sleeve monopole antennas," IET Microwaves, Antennas \& Propagation, vol. 2, no. 6, pp. 601-605, August 2008.

[12] E. L. Chuma, Y. Iano, D. Pajuelo, G. G. Oliveira, "Design of ultra-widebend textile antenna for TV broadcasting," International Journal of Broadcast Engineereing (IJBE), vol. 5, no. 9, pp. 74-77, Setember 2019.

[13] D. Okamoto, L. S. Mello, M. Almeida, C. Rodriguez, "Performance evaluation of digital TV and LTE systems operating in the $700 \mathrm{MHz}$ band under the effect of mutual interference," Journal of Microwaves, Optoelectronics and Electromagnetic Applications, vol. 15, no. 4,, pp. 441-456, December 2016.

[14] N. O. Cunha, M. E. Ferreira, R. M. S. de Oliveira, J. F. Almeida, C. Sobrinho, "The HI monopole," SBMO/IEEE MTT-S International Microwave and Optoelectronics Conference (IMOC), pp. 506-509, November 2009.

[15] P. Beigi, Y. Zehforooshb, J. Nourinia, "Enhanced bandwidth reconfigurable single and dual band-notch antenna by using DGS for UWB and KU applications," Journal of Instrumentation, vol. 14, pp. 1-8, February 2019.

[16] A. P. Padmavathy, M. G. Madhan, "An improved UWB patch antenna design using multiple notches and finite ground plane," Journal of Microwaves, Optoelectronics and Electromagnetic Applications, vol. 14, no. 1, pp. 133-142, June 2015.

[17] H. Schantz, "The art and science of ultra-wide band antennas," Artech House, 1955. 